\title{
The proportionality principle and what it means in practice
}

\author{
Martin Curtice, ${ }^{1}$ Fareed Bashir, ${ }^{2}$ Sanjay Khurmi, ${ }^{3}$ Juli Crocombe, ${ }^{4}$ Tim Hawkins, $^{5}$ Tim Exworthy $^{6}$
}

The Psychiatrist (2011), 35, 111-116, doi: 10.1192/pb.bp.110.032458

${ }^{1}$ Hollyhill Unit, Birmingham;

${ }^{2}$ Prestwich Hospital, Manchester;

${ }^{3}$ Crisis Resolution Home Treatment

Team, Coventry; ${ }^{4}$ St George's

Hospital, Stafford; ${ }^{5}$ Mount Gould

Hospital, Plymouth; ${ }^{6}$ Memorial

Hospital, London

Correspondence to Martin Curtice

(mjrc@ukonline.co.uk)

First received 24 Aug 2010, accepted

22 Oct 2010
Summary The Mental Health Act 2007 and the Mental Capacity Act 2005 have been made compatible with the European Convention on Human Rights (as enacted in the UK by the Human Rights Act 1998). The respective Codes of Practice have now embedded within them a human rights-based approach. Central to this is the principle of proportionality, which is regarded as the dominant theme underlying the Convention. This article explores the legal basis of proportionality, specifically analysing its use in relation to the Mental Health Act and the Mental Capacity Act. In doing so, it considers the use of the principle of proportionality in clinical practice.

Declaration of interest None.
The Human Rights Act 1998 incorporates most of the European Convention on Human Rights ('Convention') into UK law. The Act applies to all courts and tribunals, including mental health tribunals, and all UK law and legislation is expected to be compatible with the Act. This has been made evident with the advent of the Mental Capacity Act 2005 and the Mental Health Act 2007, as the respective Codes of Practice $^{1,2}$ describe human rights aspects in the implementation of both Acts.

The Convention, and hence the Human Rights Act, is underpinned by core principles, of which proportionality (although not specifically mentioned within the text of the Convention) is well established ${ }^{3,4}$ and regarded as the dominant theme underlying the Convention. ${ }^{5}$ The importance of proportionality has been elucidated in the decision-making guidance in both the Mental Capacity Act and Mental Health Act. This article will describe the central legal tenets of proportionality, analyse its use as advocated by the Mental Health Act and Mental Capacity Act, and consider its application in clinical practice.

\section{Proportionality - legal basis}

The European Court of Human Rights has noted that 'inherent in the whole of the Convention is a search for a fair balance between the demands of the general interest of the community and the requirements of the protection of the individual's fundamental rights, ${ }^{6,7}$ Such a fair balance is struck by the application of the principle of proportionality. The principle applies equally to capacitious and incapacitous individuals alike. The European Convention on Human Rights aims to ensure that the limitations placed upon an individual's protected rights are imposed only if they are:
- in accordance with the law, such as the Mental Health Act or Mental Capacity Act

- intended to achieve a legitimate objective, for example treatment, safety of the individual, safety of others

- necessary in a democratic society.

It is this final requirement which subsumes the principle of proportionality.

Proportionality can apply to a myriad of situations and is most commonly associated with the balancing exercise in determining claims under 'qualified' Convention rights (those which permit the State's lawful interference in certain circumstances). In clinical practice, this mainly applies to Article 8 (the right to respect for family and private life, home and correspondence), ${ }^{\text {a }}$ Article 9 (freedom of thought, conscience and religion) and Article 10 (freedom of expression).

Proportionality requires that decision makers considering an interference with a Convention right must balance the severity of the interference with the intensity of the social need for action. In essence, they must decide whether interference with a person's rights is justified. This aims to protect individuals from arbitrary decisions. The State must not act disproportionately to achieve a legitimate aim. Case law has elucidated that a sliding scale applies to the use of proportionality, in that the more substantial the interference the more that is required to justify it' ${ }^{9}$ and in particular the State must 'not use a sledgehammer to crack a nut'. ${ }^{10}$ The burden lies on the State to justify whether an interference is proportionate.

Case law ${ }^{11,12}$ has evolved and produced a four-pronged test of proportionality ('Huang test').

- Does the policy (or measure) in question pursue a sufficiently important objective?

a. For a review of Article 8 mental health case law, see Curtice. ${ }^{8}$ 
- Is the rule or decision under review rationally connected with that objective?

- Are the means adopted no more than necessary to achieve that objective?

- Does the measure achieve a fair balance between the interests of the individual(s) affected and the wider community (i.e. a question of whether a measure constitutes a proportionate means of achieving a legitimate aim)?

This test offers a structured and rigorous approach and is becoming more widely applied. ${ }^{13}$ Despite this, some experts describe proportionality as still being 'not an exact science. ${ }^{13}$ Often in complex or difficult clinical cases the principle of proportionality, and indeed the Huang test, may be important in choosing between various treatment options for individuals. This may mean settling for the least restrictive or 'least drastic'll option of a series of potential therapeutic interventions.

\section{Proportionality and the Mental Health Act}

The Mental Health Act Code of Practice subsequent to the Mental Health Act 2007 elucidates various circumstances where proportionality should be considered. ${ }^{2}$

\section{Confidentiality}

A person's right to have their privacy respected is protected by Article 8 of the European Convention on Human Rights. The disclosure of confidential information may breach Article 8, unless it is a necessary and proportionate response to a specific situation. The Mental Health Act Code considers issues about confidentiality and information sharing arising in connection with the Act. It notes that there are circumstances in which it is both justifiable and important to share otherwise confidential patient information with people outside the immediate team treating a patient. Should the individual be incapable to consent to disclosure, then disclosure can be made in their best interests. The Code notes that confidential patient information may be disclosed outside the team only under certain circumstances:

- if the person has given their consent (where the person has capacity to consent)

- if there is a specific legal obligation or authority to do so

- where there is an overriding public interest in disclosing the information.

The Code further notes that the Mental Health Act recognises a number of situations where confidential information about patients will need to be disclosed, even without the person's consent (paragraph 18.6). These include:

- reports to the mental health tribunal when a patient's case is to be considered

- reports to the Equality and Human Rights Commission in relation to individuals who have been treated on the basis of a certificate issued by a second-opinion appointed doctor
- reports to the Secretary of State for Justice on restricted patients under the Mental Health Act.

\section{Information for the nearest relative}

The Mental Health Act requires that information be supplied to the nearest relative, unless the patient requests otherwise, when a patient is detained under the Mental Health Act or on supervised community treatment (SCT), or discharged from detention or SCT (Mental Health Act regulations also require nearest relatives to be informed of various other events, including the renewal of a person's detention, extension of SCT and transfer from one hospital to another). These duties to inform nearest relatives are not absolute and in almost all cases information is not to be shared if the patient objects (2.31). In addition, there will occasionally be cases where these duties do not apply because disclosing information about the patient to the nearest relative cannot be considered practicable, on the grounds that it would have a detrimental impact on the patient that is disproportionate to any advantage to be gained from informing the relative. This would, therefore, be a breach of the patient's right to privacy under Article 8 .

\section{Interventions where de-escalation is insufficient}

Clinical interventions such as physical restraint, seclusion or rapid tranquillisation should only be considered if de-escalation and other strategies have failed to calm the person (15.17). The Mental Health Act Code opines that the most common reasons for needing to consider such interventions are: physical assault; dangerous, threatening or destructive behaviour; self-harm or risk of physical injury by accident; extreme and prolonged overactivity that is likely to lead to physical exhaustion; attempts to abscond.

The Code further advises that the intervention chosen must balance the risk to others with the risk to the patient's own health and safety and must be 'a reasonable, proportionate and justifiable response to the risk posed by the patient' (15.19).

\section{Privacy and safety}

The Code addresses privacy and safety in hospitals for patients detained under the Mental Health Act, including access to telephones and IT equipment, and the use of searches. This is subsumed under Article 8. In relation to acute wards, the Code recognises the complex and specific needs of patients admitted to such wards, whether or not they are formally detained, and in particular how ward staff in such environments must balance competing priorities and interests when assessing and determining what safety measures are needed (16.34). The Code notes the intention should be to protect patients, especially those who are at risk of suicide, self-harm, accidents or inflicting harm on others unless they are prevented from leaving the ward. Furthermore, the Code suggests that arrangements should not aim to impose any unnecessary or disproportionate restrictions on patients or to make them feel as though they are subject to such restrictions. 


\section{Personal and other searches}

The Code notes that hospital managers should ensure there is an operational policy on searching patients detained under the Mental Health Act, their belongings and surroundings, as well as their visitors. Two of the four principles underpinning such policies are that the search of a person or their property should be proportionate to the identified risk and should involve the minimum possible intrusion into the person's privacy. All searches should be undertaken with due regard to, and respect for, the person's dignity (16.11). A general policy of searching detained patients in order to maintain a safe therapeutic environment is implied by the Mental Health Act. The intrusiveness of the searching needs to be proportionate to the circumstances in which the person is detained. ${ }^{14}$

\section{Treatment without consent}

The Code provides salient advice regarding the treatment of patients without their consent (Section 63) in terms of the European Convention on Human Rights. It notes that clinicians who authorise or administer treatment without consent under the Mental Health Act are performing a function of a public nature and are, therefore, subject to the provisions of the Human Rights Act. The Code further notes that it would be unlawful for a clinician 'to act in a way which is incompatible with a patient's rights as set out in the ECHR' (23.39). It also describes the importance of proportionality and of the rights enshrined in Article 3 (freedom from inhuman and degrading treatment) ${ }^{15}$ and Article 8 in such decision-making $(23.40,23.41)$ (Box 1).

Box 1 Treatment without consent under the Mental Health Act - ECHR implications and Mental Health Act Code of Practice advice

- Compulsory administration of treatment which would otherwise require consent is invariably an infringement of Article 8 of the ECHR (respect for family and private life). However, it may be justified where it is in accordance with law (in this case, the procedures in the Mental Health Act) and where it is proportionate to a legitimate aim (in this case, the reduction of the risk posed by a person's mental disorder and the improvement of their health).

- Compulsory treatment can sometimes be perceived as inhuman (or, in extreme cases, even torture), contrary to Article 3 of the ECHR, if its effect on the person concerned reaches a sufficient level of severity. However, the European Court of Human Rights has stated that a measure which is convincingly shown to be of therapeutic necessity from the point of view of established principles of medicine cannot, in principle, be regarded as inhuman and degrading. ${ }^{16}$

- Scrupulous adherence to the requirements of the legislation and good clinical practice should help ensure there is compatibility between the Mental Health Act and the ECHR. If clinicians have concerns about a potential breach of a person's human rights, they should seek senior clinical and, if necessary, legal advice.

ECHR, European Convention on Human Rights.

\section{Emergency treatment under Section 64G of the Mental Health Act}

The Mental Health Act Code refers to individuals on SCT who have not been recalled to hospital as 'Part 4A patients'. The rules for treatment of such individuals differ depending on whether or not they are able to consent to the treatment in question. Part 4A patients who lack capacity (and who have not been recalled to hospital) can, in an emergency, be given treatment by anyone, whether or not they are acting under the direction of an approved clinician (23.21). The Code elucidates when treatment should be given in an emergency (23.22) (Box 2). When treatment is 'immediately necessary' it can be given even though it may conflict with an advance decision or the decision of someone who has authority under the Mental Capacity Act to refuse treatment on the patient's behalf (23.23). Force may be used, whether or not the patient objects, provided that the treatment is necessary to prevent harm to the patient and the force used is proportionate to the likelihood of the patient suffering harm and to the seriousness of that harm.

Although treatment is being provided as an emergency, there is still a high threshold before it can be given and then the proportionality principle dictates the degree of intrusion that can be allowed. These are the only circumstances in which force may be used to treat individuals on SCT who object without recalling them to hospital (23.25). These 'exceptional' situations occur when the individual's best interests would be better served by administering urgently needed treatment by force outside hospital rather than recalling the person to hospital, for instance if taking them to hospital would exacerbate their condition, impair or damage their recovery or cause them unnecessary anxiety or suffering; or where the situation is so urgent or critical that recall is unrealistic.

Box 2 Emergency treatment for Part 4A patients who lack capacity to consent

It is an emergency only if the treatment is immediately necessary to:

- save the patient's life;

- prevent a serious deterioration of the patient's condition, and the treatment does not have unfavourable physical or psychological consequences which cannot be reversed;

- alleviate serious suffering by the patient and the treatment does not have unfavourable physical or psychological consequences which cannot be reversed and does not entail significant physical hazard;

- prevent the patient behaving violently or being a danger to themselves or others, and the treatment represents the minimum interference necessary for that purpose, does not have unfavourable physical or psychological consequences which cannot be reversed and does not entail significant physical hazard.

If the treatment is ECT (or medication administered as part of ECT), only the first two categories above apply.

ECT, electroconvulsive therapy. Source: Mental Health Act Code of Practice. $^{2}$ 


\section{Supervised community treatment}

The supervised community treatment order (CTO) will inevitably impinge on an individual's human rights (Article 8 and, to a lesser extent, Article 5: the right to liberty). Getting the right balance in imposing the CTO and associated conditions can be a difficult process, which can be aided by the principle of proportionality. The imposition of a CTO and associated conditions is dependent on a number of criteria, with guidance offered by the Mental Health Act Code of Practice.

When considering a CTO, items 3 and 4 of the Huang test appear to aid decision-making - a proportional decision is least restrictive for the person bearing in mind their needs and the needs of the wider community. How is this process met in clinical practice? Initially, it is important to consider all information relevant to the decision (the Code offers guidance as to what is important, 25.8-13). Viable, less restrictive alternatives to the CTO (i.e. guardianship, Section 17 leave) need explicit thought, as do conditions attached to the CTO. Article 8 can be substantially impeded by the latter. The Code states that CTO conditions 'might cover matters such as where and when the patient is to receive treatment in the community; where the patient is to live; and avoidance of known risk factors or high-risk situations relevant to the patient's mental disorder' (25.34). Conditions for the CTO should be kept to a minimum and restrict a patient's liberty as little as possible. The involvement of the approved mental health professional (required by law), the patient and any other relevant parties in decision-making is essential in ensuring a holistic, proportional approach.

\section{Recall to hospital of individuals on supervised community treatment orders (Section 17E Mental Health Act)}

The recall to hospital of individuals on SCT also involves an approach incorporating proportionality. The Mental Health Act Code observes that the recall power is intended to provide a means to respond to evidence of relapse or highrisk behaviour relating to mental disorder before the situation becomes critical and leads to the patient or other people being harmed' (25.47). The patient must 'always be given the opportunity to comply with the [CTO] condition before recall is considered' (25.49) and the responsible clinician 'must be satisfied that the criteria are met before using the recall power' (25.50). Action taken should be proportionate to the level of risk. For some individuals, the risk arising from a failure to adhere to treatment could indicate an immediate need for recall, but in other cases, negotiation with the person - and with their nearest relative and/or carer (unless the person objects or it is not reasonably practicable) - may resolve the problem and so avert the need for recall (25.50). Proportionality refers to both the immediacy and the severity of the risk. Thus a low probability of severe harm being caused could lead to recall, whereas a higher probability of less serious harm being caused might not.

\section{Proportionality and the Mental Capacity Act}

The Mental Capacity Act similarly embeds within its Code of Practice ${ }^{1}$ central tenets of the Human Rights Act and proffers advice regarding proportionality. Predictably, it addresses the issue of physical restraint and advocates that restraint may only be used where it is 'necessary to protect the person from harm and is proportionate to the risk of harm' (6.11). A 'proportionate response' as stated in the Code means 'using the least intrusive type and minimum amount of restraint to achieve a specific outcome in the best interests of the person who lacks capacity' (6.47). In circumstances when the use of force may be necessary, the Code notes that carers and healthcare and/or social care staff should use 'the minimum amount of force for the shortest possible time' (6.47). This is illustrated by describing how a carer may need to hold a person's arm while they cross the road when a person does not understand how safely to do so. It would not be a proportionate response to negate the risk by stopping the person from going outdoors completely, but it may be appropriate to have a secure lock on a door that faces a busy road. The Mental Capacity Act Code advocates that carers and healthcare or social care staff should 'consider less restrictive options before using restraint' and, where possible, seek the views of others who are involved in the person's care as to what action they think may be necessary to protect them from harm (e.g. engaging an advocate to work with the person might help minimise, if not avoid completely, the need for restraint) (6.48).

Proportionality is also central to the implementation of the deprivation of liberty safeguards (DoLS) enacted under the Mental Capacity Act. The associated DoLS Code of Practice ${ }^{17}$ makes it clear that 'a person may only be deprived of their liberty:

- in their own best interests to protect them from harm

- if it is a proportionate response to the likelihood and seriousness of the harm, and

- there is no less restrictive alternative' (1.13).

The best interests assessment for the purpose of DoLS is an assessment of whether deprivation of liberty is: in a relevant person's best interests; necessary to prevent harm to the person; and a proportionate response to the likelihood and seriousness of harm to the person (4.58). ${ }^{17}$

The Mental Capacity Act Code also considers proportionality with respect to an incapacitated person who needs a change of residence when they cannot be supported in their own home and may need to move to live with relatives or move to a care home (6.8). For such an incapacitated person, Section 5 of the Mental Capacity Act allows carers to carry out actions relating to the move provided that the Act's principles and the person's best interests requirements have been followed; those provisions apply even if the person objects (6.11). Section 6 of the Mental Capacity Act, however, places 'clear limits' on the use of force or restraint in such cases (e.g. when transporting the person to their new home). Thus, restraint can only be used to protect the person from harm and only as a proportionate response to the risk of harm (6.11). 
Box 3 Clinical situations where proportionality may be important in relation to hospital patients' management

- Physical restraint - may include the use of handcuffs for detained patients attending courts; the use of protective helmets or arm splints for patients with learning disabilities who have severe repetitive self-harming behaviour; transfer of incapacitated patients into care homes when their home circumstances become untenable

- Seclusion and rapid tranquillisation - both the type of circumstances and the extent to which seclusion and rapid tranquillisation are used

- Confidentiality - information sharing, for instance with the nearest relative, between interested parties or agencies

- Personal searches

- Mental health tribunals - the degree of caution being exercised in agreeing to the discharge of detained patients

- Supervised community treatment orders (CTO) and recall of CTO patients - emergency treatment for Part 4A patients who lack capacity to consent

- Privacy - no conjugal family visits; lack of access to telecommunications or 'routine' entertainment systems (e.g. television, radio, telephone, internet)

- Smoking - no-smoking policies; preventing incapacitated patients from smoking if their physical health is directly at risk

- Zone of parental control - under this new concept introduced under the Mental Health Act 2007, decision-making for medical treatment plans for under-16-year-olds may well involve an approach using proportionality

- Diet - restriction of diet/promotion of healthy eating for incapacitated patients who are obese, which puts their health at risk or has a severe impact on their quality of life

- Community access - accompanying incapacitated patients who have poor road safety skills or are at risk of exploitation in the community; locked door policy for vulnerable patients

- Change of residence - deciding in the best interests of incapacitated patients to place them into a care home when living in their own home becomes untenable

\section{Discussion}

The culture of respect for human rights has 'largely failed to take root among public authorities ${ }^{18}$ in the UK since the inception of the Human Rights Act 1998. This failure has subsequently contributed to the poor public image of the Act and human rights in general. ${ }^{19}$ Despite this, evidence suggests that 'a human rights framework helps staff to reach objective, balanced and proportionate solutions to seemingly insoluble problems and to be more confident in their decision-making, ${ }^{18}$ New statute in the form of the Mental Health Act 2007 and the Mental Capacity Act 2005 have needed to be compliant with the European Convention on Human Rights and, as seen in the respective Codes of Practice, a human rights based-approach with the core concept of proportionality is now embedded within both Acts. ${ }^{\mathrm{b}}$ An analysis of both Codes of Practice demonstrates

b. A human rights-based approach to healthcare has been reviewed in The Psychiatrist by Curtice \& Exworthy. ${ }^{20}$

\section{Box 4 Proportionality (Huang) test in clinical practice}

1 Does the policy (or measure) in question pursue a sufficiently important objective? In clinical practice, this will invariably be in relation to treatment and management plans for patients under either the Mental Health Act or the Mental Capacity Act (e.g. compulsory detention of a person in hospital under the Mental Health Act, in order to receive treatment).

2 Is the rule or decision under review rationally connected with that objective? In essence, this ensures a decision is not arbitrary. Again, this will inevitably be in relation to patient treatment and management issues (e.g. detaining a non-adherent patient in hospital in order to treat them compulsorily).

3 Are the means adopted no more than necessary to achieve that objective? In practice, this will be assessing the least restrictive or least worst option from a range of potential options (e.g. deciding whether the compulsory admission should be to an open or a locked ward, and if the latter, how long should that be for before a transfer to an open ward could take place).

4 Does the measure achieve a fair balance between the interests of the individual(s) affected and the wider community? This final limb of the test assesses whether a clinical intervention is a proportionate means of achieving a legitimate aim. It will be particularly relevant to cases which involve a potential risk to the public, for example whether or not a forensic patient should be escorted on community leave. The question that needs to be asked is whether the restriction of the patient's rights is proportionate in relation to the risks to the public. An multidisciplinary team approach with explicit consideration of risks and restrictions on rights would help achieve a clinically proportional decision.

the importance and pervasiveness of proportionality with respect to the implementation of the Acts and its overall diversity of use clinically (Box 3).

Although there is, as yet, no single formulation of the proportionality principle, ${ }^{21}$ the four-pronged Huang test can be applied for clinical use (Box 4).

Proportionality is probably a concept already used by clinicians, albeit not so consciously employed or with a structure as that of the Huang test. Proportionality as a concept, and in particular the Huang test, lends itself well to either individual clinician or multidisciplinary team decision-making processes. This may involve generating a list of a variety of interventions for a specific clinical situation and selecting the least restrictive or 'least worst' option. This can help ensure that all the relevant issues for a particular scenario are considered and the proportionality principle helps attribute the correct emphasis to the most important factors. Clinical situations are fluid and a proportionality approach may need to be used sequentially as a situation changes. It may be that a situation is so complex or critical that there are few options from which to choose and those available may seem severe or drastic. However, the application of a structured proportionality test may enhance and, indeed, simplify complex decisionmaking processes where there may be various interacting or competing factors. The concept can also be of particular use, 
and may be referred to, when elucidating appropriate treatment and management plans for mental health tribunal and hospital managers' hearing reports, in Ministry of Justice reports for restricted patients, second-opinion approved doctor requests and in the consideration of SCT orders. This would be in keeping with the emphasis that the Mental Health Act and the Mental Capacity Act now place on both human rights and proportionality.

\section{About the authors}

Martin Curtice is consultant in old age psychiatry, Birmingham and Solihull Mental Health NHS Foundation Trust, Holyhill Unit, Rubery, Birmingham; Fareed Bashir is consultant in forensic psychiatry, Greater Manchester West Mental Health NHS Foundation Trust, Edenfield Centre, Prestwich Hospital, Manchester; Sanjay Khurmi is consultant in general adult psychiatry, Coventry and Warwickshire Partnership Trust, Crisis Resolution Home Treatment Team, Coventry; Juli Crocombe is consultant in forensic learning disability psychiatry, South Staffordshire and Shropshire Healthcare NHS Foundation Trust, St George's Hospital, Stafford; Tim Hawkins is consultant in child and adolescent psychiatry, Plymouth Hospitals NHS Trust, Mount Gould Hospital, Plymouth; and Tim Exworthy is consultant in forensic psychiatry, Oxleas NHS Foundation Trust, Memorial Hospital, London.

\section{References}

1 Department for Constitutional Affairs. Mental Capacity Act 2005 Code of Practice. TSO (The Stationery Office), 2007.

2 Department of Health. Code of Practice: Mental Health Act 1983. TSO (The Stationery Office), 2008.

3 De Burca G. The principle of proportionality and its application in EC law. Yearb Eur Law 1993; 13: 105-50.

4 McBride J. Proportionality and the European Convention on Human Rights. In The Principle of Proportionality in the Laws of Europe (ed E Ellis): 23-35. Hart Publishing, 1999.
5 Reid A. A Practitioner's Guide to the European Convention on Human Rights (3rd edn). Thomson, 2007.

6 Soering v. UK (1989) 11 EHRR 439

$7 R$ (on the application of Razgar) $v$. Secretary of State for the Home Department [2004] UKHL 27.

8 Curtice M. Article 8 of the Human Rights Act 1998: implications for clinical practice. Adv Psychiatr Treat 2009; 15: 23-31.

$9 R$ (on the application of N) v. (1) Ashworth Special Hospital Authority (2) Secretary of State for Health [2001] EWHC 339 Admin.

10 Ezeh and Connors v. The United Kingdom (2003) ECHR Application nos. $39665 / 98$ and 40086/98 9th October.

11 de Freitas v. Permanent Secretary of Ministry of Agriculture, Fisheries, Lands and Housing [1999] 1 AC 69.

12 Huang v. Secretary of State for the Home Department [2007] UKHL 11.

13 Wadham J, Mountfield H, Gallagher C, Prochaska E. Blackstone's Guide to the Human Rights Act 1998 (5th edn). Oxford University Press, 2009.

$14 R$ (on the application of $S$ and Others) v. Broadmoor Special Hospital Authority and Secretary of State for Health [1997] EWHC Admin 875

15 Curtice MJR. Medical treatment under Part IV of the Mental Health Act 1983 and the Human Rights Act 1998: review of Article 3 and 8 case law. Psychiatr Bull 2009; 33: 111-5.

16 Herczegfalvy v. Austria [1992] 15 EHRR 437.

17 Ministry of Justice. Mental Capacity Act 2005: Deprivation of Liberty Safeguards - Code of Practice to Supplement the Main Mental Capacity Act 2005 Code of Practice. TSO (The Stationery Office), 2008

18 Equality and Human Rights Commission. Human Rights in Britain since the Human Rights Act 1998: A Critical Review (Research Report 28). Equality and Human Rights Commission, 2009.

19 Joint Committee on Human Rights. The Work of the Committee in 2007 and the State of Human Rights in the UK, Sixth Report of Session 2007-08 (HL Paper 38 HC 270). TSO (The Stationery Office), 2008.

20 Curtice MJ, Exworthy T. FREDA: a human rights-based approach to healthcare. Psychiatrist 2010; 34: 150-6.

21 Goold B, Lazarus L, Swiney G. Public Protection, Proportionality, and the Search for Balance (Ministry of Justice Research Series No.10/07). Ministry of Justice, 2007 (www.justice.gov.uk/docs/270907.pdf). 